OPEN ACCESS

Edited by:

Isabelle Loubinoux,

INSERM U1214 Centre d'Imagerie

Neuro Toulouse (ToNIC), France

Reviewed by:

Svetlana Pundik,

Case Western Reserve University,

United States

Agnes Roby-Brami,

Institut National de la Santé et de

la Recherche Médicale

(INSERM), France

*Correspondence

Sheng $\mathrm{Li}$

sheng.li@uth.tmc.edu

Specialty section

This article was submitted to

Stroke,

a section of the journal

Frontiers in Neurology

Received: 31 December 2018

Accepted: 17 April 2019

Published: 10 May 2019

Citation:

Li S, Chen YT, Francisco GE, Zhou P and Rymer WZ (2019) A Unifying

Pathophysiological Account for Post-stroke Spasticity and Disordered Motor Control. Front. Neurol. 10:468. doi: 10.3389/fneur.2019.00468

\section{A Unifying Pathophysiological Account for Post-stroke Spasticity and Disordered Motor Control}

\author{
Sheng $\mathrm{Li}^{1 *}$, Yen-Ting Chen ${ }^{1}$, Gerard E. Francisco ${ }^{1}$, Ping Zhou ${ }^{1}$ and William Zev Rymer ${ }^{2}$ \\ ${ }^{1}$ Department of Physical Medicine and Rehabilitation, McGovern Medical School, University of Texas Health Science \\ Center - Houston and TIRR Memorial Hermann Hospital, Houston, TX, United States, ${ }^{2}$ Shirley Ryan Ability Lab, Chicago, IL, \\ United States
}

Cortical and subcortical plastic reorganization occurs in the course of motor recovery after stroke. It is largely accepted that plasticity of ipsilesional motor cortex primarily contributes to recovery of motor function, while the contributions of contralesional motor cortex are not completely understood. As a result of damages to motor cortex and its descending pathways and subsequent unmasking of inhibition, there is evidence of upregulation of reticulospinal tract (RST) excitability in the contralesional side. Both animal studies and human studies with stroke survivors suggest and support the role of RST hyperexcitability in post-stroke spasticity. Findings from animal studies demonstrate the compensatory role of RST hyperexcitability in recovery of motor function. In contrast, RST hyperexcitability appears to be related more to abnormal motor synergy and disordered motor control in stroke survivors. It does not contribute to recovery of normal motor function. Recent animal studies highlight laterality dominance of corticoreticular projections. In particular, there exists upregulation of ipsilateral corticoreticular projections from contralesional premotor cortex (PM) and supplementary motor area (SMA) to medial reticular nuclei. We revisit and revise the previous theoretical framework and propose a unifying account. This account highlights the importance of ipsilateral PM/SMA-cortico-reticulospinal tract hyperexcitability from the contralesional motor cortex as a result of disinhibition after stroke. This account provides a pathophysiological basis for post-stroke spasticity and related movement impairments, such as abnormal motor synergy and disordered motor control. However, further research is needed to examine this pathway in stroke survivors to better understand its potential roles, especially in muscle strength and motor recovery. This account could provide a pathophysiological target for developing neuromodulatory interventions to manage spasticity and thus possibly to facilitate motor recovery.

Keywords: spasticity, motor control, synergy, stroke, reticulospinal tract

\section{INTRODUCTION}

Stroke is a leading cause of adult disability (1). According to the centers for disease control and prevention (CDC), $\sim 800,000$ people have a stroke every year in the United States, resulting in a total of 7 million stroke survivors. Motor impairments are common, seen in about $80 \%$ of stroke survivors. Motor impairments mainly include weakness, spasticity, abnormal motor synergy, and 
disordered motor control. Spasticity and its related abnormal joint postures often interact with weakness and loss of dexterity, resulting in disordered motor control and functional limitations, such as inability to grasp, reach, walk, and transfer. Collectively, these motor impairments result in difficulties in mobility and activities of daily living, and limit their vocational and social participation in more than half of stroke survivors at age 65 and over (1). As such, these motor impairments not only have downstream effects on stroke survivors' quality of life, also lay substantial burdens on the caregivers and society (2). Numerous pharmacological agents and physical modalities and interventions have been utilized for stroke motor rehabilitation programs, but with varying degrees of success. Motor recovery after stroke still remains a clinical challenge. One of the biggest challenges is that the mechanisms underlying motor recovery are not well understood.

Neural plasticity plays an important role in motor recovery as well as development of motor complications, such as spasticity after stroke (3). Post-stroke plastic changes occur in ipsilesional, contralesional motor cortices, and subcortical areas, such as primarily pontomedullary reticular formation (PMRF) (4-21). It is largely accepted that plasticity in the ipsilesional primary motor cortex (iM1) primarily contributes to recovery of motor function, while contributions of contralesional primary motor cortex (cM1) are not completely understood. The role of $\mathrm{cM} 1$ reorganization depends on lesion location, size and motor impairment $(20,22)$. It is likely mediated by ipsilateral cortico-reticulospinal (RS) projections and uncrossed ipsilateral CST from contralesional motor cortex (19, 22-24). As a consequence of damages to iM1 and its descending pathways, both animal studies and human imaging studies suggest that there is increased excitability in the brainstem reticular system and its descending reticulospinal tract (RST) (25-27). Both animal and human studies support the maladaptive role of RS hyperexcitability in spasticity. However, animal studies have demonstrated the important role of RST in motor recovery, while its role remains controversial in human stroke studies. In this article, we first summarize experimental evidence supporting upregulations of RS excitability. The potential roles of RST in post-stroke recovery and spasticity are then compared in both animal and human stroke studies. A unifying account is proposed to better understand the brainstem roles and to consolidate controversial findings for spasticity and disordered motor control.

\section{UPREGULATION OF RETICULOSPINAL EXCITABILITY AFTER STROKE}

The reticulospinal (RS) system is another major descending system, in addition to CST. The RS system is best known for its role in posture and locomotion (28), but it also recruits both proximal and distal muscles of the upper extremity bilaterally (29), including the finger muscles $(30,31)$. There are two descending RS tracts with distinctly different origins. The dorsal RST originates from the dorsolateral reticular formation in the medulla, and receives facilitation from the motor cortex via corticoreticular fibers. The lateral CST and cortico-reticulospinal tract descend adjacent to each other in the dorsolateral funiculus at the spinal level. The medial RST originates primarily from the pontine tegmentum with connections to PMRF. The medial RST descends along with the vestibulospinal tract (VST) in the ventromedial cord. The dorsal RST provides dominant inhibitory effects to spinal reflex circuits, while medial RST and VST provide excitatory inputs. Therefore, medial and lateral RSTs provide balanced excitatory and inhibitory inputs to spinal motor neuron network. In the context of stroke with cortical and internal capsular lesions, damages often occur to both CST and corticoreticular tracts due to their anatomical proximity. This leaves the facilitatory medial RST and VST unopposed, thus hyperexcitability [see reviews in $(25-27,32)]$. However, due to technical difficulties, activities of brainstem nuclei and RST excitability cannot be localized and assessed directly in stroke survivors, even with most advanced technologies (33-37).

The RST hyperexcitability in humans has been assessed indirectly through acoustic startle reflex (ASR). ASR is an involuntary motoric response to unexpected loud auditory stimuli (38). The proposed circuit of the ASR in humans involves the cochlear nucleus, the caudal pontine reticular nuclei, the motoneurons of the brainstem, and the spinal cord activated through the medial RST (39-41). ASR has been established in the literature to investigate RST excitability in healthy and stroke subjects $(31,42-52)$. In stroke survivors with cerebral infarcts, normal ASR motoric responses could be elicited in flaccid muscles in the acute phase, however no response from the same muscles to magnetic cortical stimulation of the primary motor cortex was elicited in these patients (42), suggesting that the circuit of ASR remained intact in these patients and not under cortical control of iM1 and its descending pathways. In a different study in chronic stroke, exaggerated ASR responses were observed in spastic muscles (43), suggesting RST hyperexcitability. In a recent study (52), we compared ASR responses in chronic stroke at different stages of motor recovery (Flaccid, Spastic, and Recovered; Flaccid $=$ those who remain flaccid; Recovered $=$ those who have a history of spasticity but have recovered and have isolated voluntary movement). We found that ASR responses were within normal limits in stroke survivors without spasticity (Flaccid or Recovered). However, exaggerated ASR responses were frequently observed in spastic subjects bilaterally, but more evidently (earlier and longer duration) on the impaired side than on the non-impaired side. These results suggest that RST hyperexcitability occurs in the Spastic stages, but not in the Flaccid or Recovered stages in chronic stroke.

\section{CONTROVERSIAL ROLES OF RETICULOSPINAL TRACTS IN MOTOR RECOVERY AND DISORDERED MOTOR CONTROL}

Accumulated evidence from animal studies appears to support the role of RS hyperexcitability in motor recovery after CST damage due to stroke $(29,53-56)$. Riddle and Baker (56) reported 
that medial RS and corticospinal pathways descended in parallel and had largely overlapping effects on spinal interneurons and motoneurons in non-human primates; importantly, responses from spinal motoneurons to stimulation of either pathway at supraspinal levels were of similar amplitudes during a reach and grasp task. Buford and colleagues further reported a significantly increased RS motor output that contributed to recovery of voluntary motor control in monkeys with significantly damaged primary motor cortex and its descending CST (57, 58). For example, Buford et al. reported that, reaching was severely impaired after a substantial focal ischemic M1 lesion in an adult macaque. However, reaching performance had a near normal recovery after 12 weeks of intensive therapy. This improvement was paralleled with significantly increased output from the reticulospinal system, while little to no change was observed in both ipsilesional and contralesional M1 (58). Therefore, strengthening the existing intact RS projections is a plausible mechanism for motor recovery as seen in these animal models (56-60).

These findings do not translate into clinical practice. Studies with stroke survivors have demonstrated that RST may not always be beneficial $(22,61)$. Byblow et al. suggested that the contralesional motor cortex facilitates the descending ipsilateral cortico-reticulo-spinal projections or cortico-reticulopropriospinal projections after stroke. These projections may contribute to motor recovery in patients with severe paresis, but not in the less impaired limb $(22,62)$.

The possible contributions to force production from cM1 and its descending ipsilateral cortico-reticulo-spinal pathways seem insignificant, however. The contributions were examined in a recent TMS study (63). TMS to cM1 was delivered during isometric elbow flexion at submaximal levels on the spasticparetic side in chronic stroke and in healthy subjects. The TMS-induced force increment was significant greater only at $10 \%$ of maximal voluntary contraction tasks in stroke subjects than in healthy controls. No significant difference in the force increment was found at higher force levels. In a recent study, during isometric elbow flexion tasks, the force increment induced by stimulation of RST via startling acoustic sound in stroke survivors with spastic elbow flexors was not significantly different from the increment in neurologically intact subjects (64). Taken together, these findings indicate that RST hyperexcitability does not provide additional contributions to voluntary elbow flexion force production in chronic stroke survivors.

On the other hand, RS hyperexcitability is associated with abnormal motor synergy and disordered motor control in chronic stroke survivors. In a DTI study, RST reorganization and strengthening is significantly correlated with impairments and abnormal synergy, not motor recovery (24). In a series of studies by Dewald and colleagues $(24,65-71)$, they have consistently reported involvement of RS hyperexcitability in abnormal synergy in shoulder, elbow, wrist and finger movement on the paretic side in chronic stroke with moderate to severe motor impairment. Specifically, they provide evidence that contralesional cortico-reticulospinal pathways are progressively recruited, but they do not contribute to discrete voluntary movement (70).
RS hyperexcitability seems to be maladaptive in the course of complete motor recovery. In a recent longitudinal study in 2018 (21), the authors tracked the time course of mirror movement in the non-paretic hand during individual finger movement of the paretic hand in stroke survivors since 2 weeks post stroke. They reported mirroring in the non-paretic hand was exaggerated early after stroke, but progressively improved over the year. The improvement paralleled individuation deficits in the paretic hand in the time course. However, these changes were not concomitantly accompanied by any evidence of cortical mechanisms according to fMRI data. The authors attributed these changes to upregulation of subcortical mechanisms, particularly RS hyperexcitability in the early recovery phase. During the course of recovery, improvement in mirroring reflects the reliance on the capacity of cortical sensorimotor areas in both hemispheres to re-gain modulatory influences on the RST.

\section{THE ROLE OF RST HYPEREXCITABILITY IN POST-STROKE SPASTICITY}

Post-stroke spasticity is a common phenomenon of velocitydependent increase in resistance when a joint is passively stretched. It is accepted that spasticity is mediated by exaggerated spinal stretch reflex $(25-27,32,72,73)$. Animal lesion studies in last century have provided strong experimental evidence to support the role of RST hyperexcitability in spasticity. For example, isolated lesions to CST only produce weakness, loss of dexterity, hypotonia, and hyporeflexia, instead of spasticity (74-76). Surgical section of unilateral or bilateral VST in the anterior cord has little effect (77) or a transient effect (78) on spasticity. With more extensive cordotomies that damage the medial RST, spasticity is dramatically reduced (78). In another study, Burke et al. provided evidence that spasticity and decerebrate rigidity are differentially mediated through RST and VST projections (79).

Overall, findings from studies with human subjects are consistent with findings from animal studies on the role of RST for spasticity. As mentioned earlier, there are exaggerated acoustic startle reflexes in stroke survivors with spasticity $(43,52)$. The RST plays an important role in maintaining joint position and posture against gravity (28). The findings of high correlations between the resting joint of elbow joint and severity of spasticity (clinical and biomechanical measurements) (80) suggest that post-stroke spasticity is strongly related to RS hyperexcitability and its antigravity effects.

The descending medial RST inputs to the spinal motor neurons from medial PMRF are primarily mediated by the monoamines serotonin (5-HT) and norepinephrine (NE). The monoaminergic inputs via unopposed hyperexcitable RST provide powerful neuromodulatory changes of spinal motor neurons, greatly increasing their excitability and facilitating persistent inward currents (PIC) (81-83). The PIC is a depolarizing current generated by voltage-activated channels that tend to remain activated, thus associated 
with a plateau behavior (84). PICs are associated with subthreshold depolarization of spinal motor neurons, and hyperactive stretch reflexes in the spastic-paretic limb following stroke, thus mediating spasticity. A serotonergic agent (estitalopram) can augment spasticity (85), while an anti-serotonergic agent (cyproheptadine) facilitates relaxation time of spastic muscles (86). Reduction in descending NE drive via administration of tizanidine has shown to improve independent joint control in chronic stroke survivors with moderate to severe motor impairments (87).

Given unilateral nature of VST projections (88), the role of VST in spasticity was recently tested in chronic stroke $(89,90)$, in which VST was stimulated via high-level acoustic stimuli $(130 \mathrm{~dB})$. The results showed a strong correlation between triggered responses and overall severity of spasticity, thus suggesting the role of hyperexcitability of VST in spasticity. Yet this level of acoustic stimuli is also likely to activate RST pathways $(39,91)$. The role of VST in spasticity cannot be ruled out in human subjects. It is possible that VST affects spasticity via the VST-RST connectivity as mentioned above (92). As mentioned earlier, the findings from animal study do not support the role of VST in spasticity. Findings from advanced neuroimaging study in chronic stroke with severe motor impaired fail to reveal increased VST size as well (24).

\section{A UNIFYING ACCOUNT FOR SPASTICITY, MOTOR RECOVERY, AND DISORDERED MOTOR CONTROL}

In summary, findings from both animal studies and studies with human subjects support the role of RST hyperexcitability in post-stroke spasticity. In contrast, the compensatory role of RST hyperexcitability in motor recovery is only documented in animal studies, while RST hyperexcitability is more likely related to abnormal synergy and disordered motor control, but not to recovery of voluntary movement in stroke survivors. Both RST and CST work together to recruit muscles during voluntary movement. RST is known of particular importance in concert with actions of the ipsilateral CST (93). For example, in chronic stroke survivors, it was found that the fiber volume of ipsilateral corticoreticular projections from the contralesional hemisphere was increased, and such change was correlated to walking ability (19). In another study (94), findings suggested a relationship between increased activity in the contralesinal cortical areas (M1, premotor, and primary sensory cortex) and spasticity mitigation in response to motor learning therapy in chronic stroke. However, efforts and strategies to promote motor recovery have focused mainly on iM1 and cM1, for example, they are targets of noninvasive brain stimulation (95-97). The RST involvement is considered beneficial in those with severe motor impairment (22). In contrast, RST hyperexcitability has been emphasized to likely mediate post-stroke spasticity $(25-27,32)$. It lacks a theoretical framework to understand the role of the brainstem

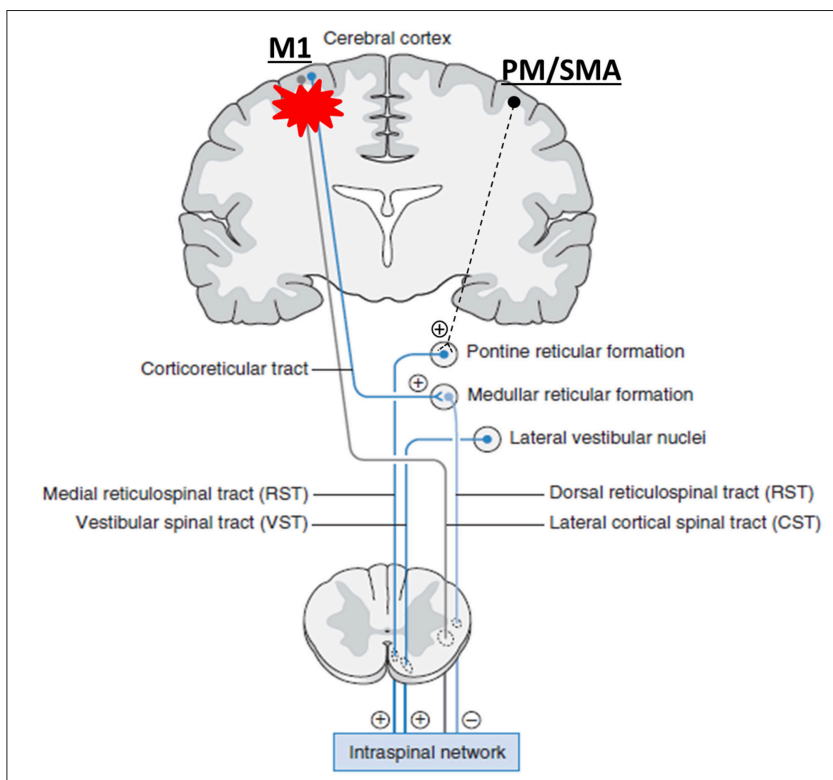

FIGURE 1 | A unifying pathophysiological account for post-stroke spasticity, abnormal synergy, and disordered motor control. For the medial PMRF, it receives inputs primarily from ipsilateral premotor $(\mathrm{PM})$ and supplementary motor area (SMA), and descends ipsilaterally. This medial cortico-reticulo-spinal tract (CRST) provides excitatory descending inputs to spinal motor neurons. The dorsolateral PMRF receives inputs primarily from contralateral primary motor cortex (M1). This dorsal CRST provides inhibitory descending inputs to the spinal motor circuitry. When damages occur to the corticospial tract (CST) and CRST after stroke on one hemisphere (red asterisk), their output signals diminish. Subsequently, the medial CRST excitability of the contralesional hemisphere becomes unopposed, upregulated gradually, and hyperexcitable. Eventually, spinal motor neurons are hyperexcitable, or may be spontaneously firing. (+): excitatory; (-): inhibitory. Note: other descending pathways are not illustrated. They are considered either insignificant or connected with the reticulospinal tract [modified from Francisco and Li (98)].

reticulospinal system and its interactions with the corticospinal motor system in motor recovery, disordered motor control, and spasticity.

Recent research findings provide new insights into understanding the role of RST and its interactions with CST in stroke survivors. It was believed that the ventromedial reticular formation in the medulla receives the excitatory inputs vial corticoreticular projections from the contralateral M1 and gives out dorsal RST and descends ipsilaterally next to the lateral CST; while the medial RST originates diffusely within medial pontomedullary reticular formation (PMRF) (25-27, 32). After stroke-related damage to the M1 and its descending CST and corticoreticular projections, the medial RST becomes unopposed and gradually hyperexcitable, providing excitatory inputs to the spinal motor neurons (see Figure 1 without dashed projection from PM/SMA) (25-27, 32). Recent studies demonstrate that cortico-reticulospinal projections are bilateral, but have laterality dominance (99-101). For the medial PMRF, it receives inputs primarily from ipsilateral premotor (PM) and supplementary motor area (SMA), and descends ipsilaterally to the spinal cord. 
This medial cortico-reticulo-spinal tract (CRST) provides excitatory descending inputs to spinal motor neurons. The dorsolateral PMRF receives inputs primarily from contralateral primary motor cortex (M1). This dorsal CRST provides inhibitory descending inputs to the spinal motor circuitry. Following focal cortical lesions in monkeys, there are reports of upregulation of contralateral SMA/PM-corticoreticular projections (100-102). Taken these findings into consideration, we propose a unifying account in understanding the role of RST hyperexcitability in post-stroke spasticity, abnormal synergy, and disordered motor control. Figure 1 schematically illustrates this account. As compared to previous accounts, the novel addition is that the medial PMRF receives excitatory inputs primarily from the ipsilateral PM and SMA of the contralesional cortex. In addition to further support the role of RST hyperexcitability in spasticity as in previous accounts, this unifying account provides a theoretical framework to understand the role of RST hyperexcitability and its interactions with bilateral motor cortices in motor recovery and abnormal synergies.

\section{Abnormal Motor Synergy and Disordered Motor Control}

The RST has diffuse and divergent projections to multiple synergic muscles. Given the resultant hyperexcitable spinal motor neurons, attempts to voluntarily activate a spastic muscle often result in synergistic activation of multiple spastic muscles, i.e., abnormal motor synergy. This phenomenon has been consistently reported by Dewald and colleagues (24, 65-71). The abnormal coupling of muscle activation has also been found between upper and lower extremities (103) and between two upper extremities (104). Therefore, motor synergies are simplified and more stereotyped gait patterns are seen in stroke survivors with spasticity (105). Similarly, inter-joint coordination between spastic muscles is impaired, leading to disordered motor control (106-109). Furthermore, it is conceivable that PM/SMA and cM1 are both activated during voluntary elbow flexion on the less-affected side, thus subsequently activating ipsilateral spastic muscles involuntarily via the PM/SMA-CRST projections, i.e., motor overflow (110).

\section{Motor Recovery}

RST excitability increases along with the emergence of poststroke spasticity and subsides in the recovered stage. In addition, no exaggerated motor overflow is observed in stroke survivors with recovered motor function (52). This may be related to the fact that ipsilesional M1 evolves and regains cortical control of motor function as motor recovery progresses (13). As such ipsilesional M1 regains its neuromodulatory inputs to PMRF and rebalances RST influences to spinal motor networks. This could also account for disappearance of spasticity in the recovered, late Brunnstrom stages (111). However, this seemingly maladaptive RST hyperexcitability is conceivable to facilitate movement via the ipsilateral CRST. In a recent study on chronic stroke survivors with severe motor impairment, facilitatory stimulation via repetitive TMS to the dorsal premotor area on the contralesional hemisphere improved reaching time on the paretic side (20). It remains unclear whether this improvement relates to a stronger synergistic activation or improved isolate movement and strength.

\section{Muscle Strength}

There is evidence that startling acoustic stimulation enhances maximum force production in healthy subjects via stimulation of RST $(112,113)$. In chronic stroke survivors, startling acoustic sound stimulation does not cause additional force increment as compared to healthy subjects (64). Given different cortical origins for medial and dorsal PMRF areas (Figure 1), it is likely that the RST projections function to tune and modulate motor commands (114), rather to compensate for them. The StartReact phenomenon could support this view. The StartReact phenomenon refers to an early release of a motor plan during simple reaction time tasks in the presence of startling acoustic stimulation (115). This phenomenon is seen in stroke survivors as well $(46,48)$. However, no early release of motor plan is observed when no motor plan is ready in a choice reaction time task (116), or a Go/No-go reaction time task (117).

\section{Concluding Remarks}

Based on recent advances in animal studies and human studies with stroke survivors, we revisit and revise the previous theoretical framework and propose a unifying account. This account highlights the importance of ipsilateral PM/SMAcortico-reticulospinal tract hyperexcitability as a result of disinhibition after stroke. This account is able to provide a pathophysiological basis for post-stroke spasticity and related movement impairments, such as abnormal motor synergy, disordered motor control. This account could provide a pathophysiological target for neuromodulatory interventions to manage spasticity, and thus possibly to facilitate motor recovery. Some issues and controversies remain to be further addressed, such as the role of higher cortical centers (e.g., PM and SMA) and bilateral RST projections. The contributions from other descending pathways, especially VST projections need to be further studied. With advances in technologies, further research on these issues is needed to better understand the potential roles of this pathway in stroke motor recovery.

\section{AUTHOR CONTRIBUTIONS}

SL developed the initial version of the manuscript and created the figure. Y-TC, GF, PZ, and WR critically revised the manuscript and contributed substantially to the manuscript development. All authors read and approved the final manuscript.

\section{ACKNOWLEDGMENTS}

This study was supported in part by NIH NICHD/NCMRR R21HD087128, R21HD090453. 


\section{REFERENCES}

1. Benjamin EJ, Blaha MJ, Chiuve SE, Cushman M, Das SR, Deo $\mathrm{R}$, et al. Heart disease and stroke statistics-2017 update: a report from the American Heart Association. Circulation. (2017) 135:e146-603. doi: 10.1161/CIR.0000000000000491

2. Zorowitz RD, Gillard PJ, Brainin M. Poststroke spasticity: sequelae and burden on stroke survivors and caregivers. Neurology. (2013) 80:S45-52. doi: 10.1212/WNL.0b013e3182764c86

3. Li S. Spasticity, motor recovery, and neural plasticity after stroke. Front Neurol. (2017) 8:120. doi: 10.3389/fneur.2017.00120

4. Palmer E, Ashby P, Hajek VE. Ipsilateral fast corticospinal pathways do not account for recovery in stroke. Ann Neurol. (1992) 32:519-25. doi: 10.1002/ana.410320407

5. Weiller C, Ramsay SC, Wise RJ, Friston KJ, Frackowiak RS. Individual patterns of functional reorganization in the human cerebral cortex after capsular infarction. Ann Neurol. (1993) 33:181-9. doi: 10.1002/ana.410330208

6. Turton A, Wroe S, Trepte N, Fraser C, Lemon RN. Contralateral and ipsilateral EMG responses to transcranial magnetic stimulation during recovery of arm and hand function after stroke. Electroencephal Clin Neurophysiol - Electromyogr Motor Control. (1996) 101:316-28. doi: 10.1016/0924-980X(96)95560-5

7. Pineiro R, Pendlebury S, Johansen-Berg H, Matthews PM. Functional MRI detects posterior shifts in primary sensorimotor cortex activation after stroke: evidence of local adaptive reorganization? Stroke. (2001) 32:1134-9. doi: 10.1161/01.STR.32.5.1134

8. Maier MA, Armand J, Kirkwood PA, Yang HW, Davis JN, Lemon RN. Differences in the corticospinal projection from primary motor cortex and supplementary motor area to macaque upper limb motoneurons: an anatomical and electrophysiological study. Cereb Cortex. (2002) 12:281-96. doi: 10.1093/cercor/12.3.281

9. Ward NS, Brown MM, Thompson AJ, Frackowiak RS. Neural correlates of motor recovery after stroke: a longitudinal fMRI study. Brain. (2003) 126:2476-96. doi: 10.1093/brain/awg245

10. Fregni F, Boggio PS, Mansur CG, Wagner T, Ferreira MJ, Lima $\mathrm{MC}$, et al. Transcranial direct current stimulation of the unaffected hemisphere in stroke patients. Neuroreport. (2005) 16:1551-5. doi: 10.1097/01.wnr.0000177010.44602.5e

11. Mansur CG, Fregni F, Boggio PS, Riberto M, Gallucci-Neto J, Santos $\mathrm{CM}$, et al. A sham stimulation-controlled trial of rTMS of the unaffected hemisphere in stroke patients. Neurology. (2005) 64:1802-4. doi: 10.1212/01.WNL.0000161839.38079.92

12. Boudrias MH, Belhaj-Saif A, Park MC, Cheney PD. Contrasting properties of motor output from the supplementary motor area and primary motor cortex in rhesus macaques. Cereb Cortex. (2006) 16:632-8. doi: 10.1093/cercor/bhj009

13. Kim YH, You SH, Kwon YH, Hallett M, Kim JH, Jang SH. Longitudinal fMRI study for locomotor recovery in patients with stroke. Neurology. (2006) 67:330-3. doi: 10.1212/01.wnl.0000225178.85833.0d

14. Boggio PS, Nunes A, Rigonatti SP, Nitsche MA, Pascual-Leone A, Fregni F. Repeated sessions of noninvasive brain DC stimulation is associated with motor function improvement in stroke patients. Restor Neurol Neurosci. (2007) 25:123-9.

15. Dafotakis M, Grefkes C, Eickhoff SB, Karbe H, Fink GR, Nowak DA. Effects of rTMS on grip force control following subcortical stroke. Exp Neurol. (2008) 211:407-12. doi: 10.1016/j.expneurol.2008.02.018

16. Ward NS, Swayne OB, Newton JM. Age-dependent changes in the neural correlates of force modulation: an fMRI study. Neurobiol Aging. (2008) 29:1434-46. doi: 10.1016/j.neurobiolaging.2007.04.017

17. Bestmann S, Swayne O, Blankenburg F, Ruff CC, Teo J, Weiskopf N, et al. The role of contralesional dorsal premotor cortex after stroke as studied with concurrent TMS-fMRI. J Neurosci. (2010) 30:11926-37. doi: 10.1523/JNEUROSCI.5642-09.2010

18. Madhavan S, Krishnan C, Jayaraman A, Rymer WZ, Stinear JW. Corticospinal tract integrity correlates with knee extensor weakness in chronic stroke survivors. Clin Neurophysiol. (2011) 122:1588-94. doi: 10.1016/j.clinph.2011.01.011
19. Jang SH, Chang CH, Lee J, Kim CS, Seo JP, Yeo SS. Functional role of the corticoreticular pathway in chronic stroke patients. Stroke. (2013) 44:1099104. doi: 10.1161/STROKEAHA.111.000269

20. Sankarasubramanian V, Machado AG, Conforto AB, Potter-Baker KA, Cunningham DA, Varnerin NM, et al. Inhibition versus facilitation of contralesional motor cortices in stroke: deriving a model to tailor brain stimulation. Clin Neurophysiol. (2017) 128:892-902. doi: 10.1016/j.clinph.2017.03.030

21. Ejaz N, Xu J, Branscheidt M, Hertler B, Schambra H, Widmer M, et al. Evidence for a subcortical origin of mirror movements after stroke: a longitudinal study. Brain. (2018) 141:837-47. doi: 10.1093/brain/awx384

22. Bradnam LV, Stinear CM, Byblow WD. Ipsilateral motor pathways after stroke: Implications for noninvasive brain stimulation. Front Hum Neurosci. (2013) 7:184. doi: 10.3389/fnhum.2013.00184

23. Brus-Ramer M, Carmel JB, Martin JH. Motor cortex bilateral motor representation depends on subcortical and interhemispheric interactions. $J$ Neurosci. (2009) 29:6196-206. doi: 10.1523/JNEUROSCI.5852-08.2009

24. Owen M, Ingo C, Dewald JPA. Upper extremity motor impairments and microstructural changes in bulbospinal pathways in chronic hemiparetic stroke. Front Neurol. (2017) 8:257. doi: 10.3389/fneur.2017.00257

25. Brown P. Pathophysiology of spasticity. J Neurol Neurosurg Psychiatry. (1994) 57:773-7. doi: 10.1136/jnnp.57.7.773

26. Sheean G. The pathophysiology of spasticity. Eur J Neurol Supplement. (2002) 9:3-9. doi: 10.1046/j.1468-1331.2002.0090s1003.x

27. Li S, Francisco G. New insights into the pathophysiology of post-stroke spasticity. Front Hum Neurosci. (2015) 9:192. doi: 10.3389/fnhum.2015.00192

28. Drew T, Prentice S, Schepens B. Cortical and brainstem control of locomotion. Prog Brain Res. (2004) 143:251-61. doi: 10.1016/S0079-6123(03)43025-2

29. Davidson AG, Buford JA. Bilateral actions of the reticulospinal tract on arm and shoulder muscles in the monkey: stimulus triggered averaging. Exp Brain Res. (2006) 173:25-39. doi: 10.1007/s00221-006-0374-1

30. Baker SN. The primate reticulospinal tract, hand function and functional recovery. J Physiol. (2011) 589:5603-12. doi: 10.1113/jphysiol.2011.215160

31. Honeycutt CF, Kharouta M, Perreault EJ. Evidence for reticulospinal contributions to coordinated finger movements in humans. J Neurophysiol. (2013) 110:1476-83. doi: 10.1152/jn.00866.2012

32. Young RR. Spasticity: a review. Neurology. (1994) 44:S12-20.

33. D'Ardenne K, McClure SM, Nystrom LE, Cohen JD. BOLD responses reflecting dopaminergic signals in the human ventral tegmental area. Science. (2008) 319:1264-7. doi: 10.1126/science.1150605

34. Katyal S, Zughni S, Greene C, Ress D. Topography of covert visual attention in human superior colliculus. J Neurophysiol. (2010) 104:3074-83. doi: 10.1152/jn.00283.2010

35. Henderson LA, Macefield VG. Functional imaging of the human brainstem during somatosensory input and autonomic output. Front Hum Neurosci. (2013) 7:569. doi: 10.3389/fnhum.2013. 00569

36. Sulzer J, Sitaram R, Blefari ML, Kollias S, Birbaumer N, Stephan $\mathrm{KE}$, et al. Neurofeedback-mediated self-regulation of the dopaminergic midbrain. Neuroimage. (2013) 83:817-25. doi: 10.1016/j.neuroimage.2013. 05.115

37. Katyal S, Ress D. Endogenous attention signals evoked by threshold contrast detection in human superior colliculus. J Neurosci. (2014) 34:892-900. doi: 10.1523/JNEUROSCI.3026-13.2014

38. Valls-Sole J. Assessment of excitability in brainstem circuits mediating the blink reflex and the startle reaction. Clin Neurophysiol. (2012) 123:13-20. doi: 10.1016/j.clinph.2011.04.029

39. Davis M, Gendelman DS, Tischler MD, Gendelman PM. A primary acoustic startle circuit: Lesion and stimulation studies. J Neurosci. (1982) 2:791. doi: 10.1523/JNEUROSCI.02-06-00791.1982

40. Lee Y, Lopez DE, Meloni EG, Davis M. A primary acoustic startle pathway: obligatory role of cochlear root neurons and the nucleus reticularis pontis caudalis. J Neurosci. (1996) 16:3775-89. doi: 10.1523/JNEUROSCI.16-11-03775.1996

41. Koch M. The neurobiology of startle. Prog Neurobiol. (1999) 59:107-28. doi: 10.1016/S0301-0082(98)00098-7 
42. Voordecker P, Mavroudakis N, Blecic S, Hildebrand J, Zegers de Beyl D. Audiogenic startle reflex in acute hemiplegia. Neurology. (1997) 49:470-3. doi: 10.1212/WNL.49.2.470

43. Jankelowitz SK, Colebatch JG. The acoustic startle reflex in ischemic stroke. Neurology. (2004) 62:114-6. doi: 10.1212/01.WNL.0000101711.48946.35

44. Coombes SA, Janelle CM, Cauraugh JH. Chronic stroke and aging: The impact of acoustic stimulus intensity on fractionated reaction time. Neurosci Lett. (2009) 452:151-5. doi: 10.1016/j.neulet.2009.01.041

45. Honeycutt CF, Perreault EJ. Planning of ballistic movement following stroke: insights from the startle reflex. PLoS ONE. (2012) 7:e43097. doi: 10.1371/journal.pone.0043097

46. Honeycutt CF, Perreault EJ. Deficits in startle-evoked arm movements increase with impairment following stroke. Clin Neurophysiol. (2014) 125:1682-8. doi: 10.1016/j.clinph.2013.12.102

47. Tresch UA, Perreault EJ, Honeycutt CF. Startle evoked movement is delayed in older adults: implications for brainstem processing in the elderly. Physiol Rep. (2014) 2:e12025. doi: 10.14814/phy2.12025

48. Honeycutt CF, Tresch UA, Perreault EJ. Startling acoustic stimuli can evoke fast hand extension movements in stroke survivors. Clin Neurophysiol. (2015) 126:160-4. doi: 10.1016/j.clinph.2014.05.025

49. Nonnekes J, Carpenter MG, Inglis JT, Duysens J, Weerdesteyn V. What startles tell us about control of posture and gait. Neurosci Biobehav Rev. (2015) 53:131-8. doi: 10.1016/j.neubiorev.2015.04.002

50. Chen YT, Li S, Zhou P, Li S. Different Effects of Startling Acoustic Stimuli (SAS) on TMS-Induced Responses at Rest and during Sustained Voluntary Contraction. Front Hum Neurosci. (2016) 10:396. doi: 10.3389/fnhum.2016.00396

51. Chen Y-T, Li S, Zhou P, Li S. A startling acoustic stimulation (SAS)-TMS approach to assess the reticulospinal system in healthy and stroke subjects. $J$ Neurol Sci. (2019) 399:82-8. doi: 10.1016/j.jns.2019.02.018

52. Li S, Chang SH, Francisco GE, Verduzco-Gutierrez M. Acoustic startle reflex in patients with chronic stroke at different stages of motor recvoery: a pilot study. Top Stroke Rehabil. (2014) 21:358-70. doi: 10.1310/tsr 2104-358

53. Riddle CN, Edgley SA, Baker SN. Direct and indirect connections with upper limb motoneurons from the primate reticulospinal tract. J Neurosci. (2009) 29:4993-9. doi: 10.1523/JNEUROSCI.3720-08.2009

54. Sakai ST, Davidson AG, Buford JA. Reticulospinal neurons in the pontomedullary reticular formation of the monkey (Macaca fascicularis). Neuroscience. (2009) 163:1158-70. doi: 10.1016/j.neuroscience.2009.07.036

55. Herbert WJ, Davidson AG, Buford JA. Measuring the motor output of the pontomedullary reticular formation in the monkey: do stimulus-triggered averaging and stimulus trains produce comparable results in the upper limbs? Exp Brain Res. (2010) 203:271-83. doi: 10.1007/s00221-010-2231-5

56. Riddle $\mathrm{CN}$, Baker SN. Convergence of pyramidal and medial brain stem descending pathways onto macaque cervical spinal interneurons. $J$ Neurophysiol. (2010) 103:2821-32. doi: 10.1152/jn.00491.2009

57. Ortiz-Rosario A, Berrios-Torres I, Adeli H, Buford JA. Combined corticospinal and reticulospinal effects on upper limb muscles. Neurosci Lett. (2014) 561:30-4. doi: 10.1016/j.neulet.2013.12.043

58. Herbert WJ, Powell K, Buford JA. Evidence for a role of the reticulospinal system in recovery of skilled reaching after cortical stroke: initial results from a model of ischemic cortical injury. Exp Brain Res. (2015) 233:3231-51. doi: 10.1007/s00221-015-4390-x

59. Zaaimi B, Edgley SA, Soteropoulos DS, Baker SN. Changes in descending motor pathway connectivity after corticospinal tract lesion in macaque monkey. Brain. (2012) 135:2277-89. doi: 10.1093/brain/aws115

60. Fisher KM, Chinnery PF, Baker SN, Baker MR. Enhanced reticulospinal output in patients with (REEP1) hereditary spastic paraplegia type 31 . J Neurol. (2013) 260:3182-4. doi: 10.1007/s00415-013-7178-6

61. Aluru V, Lu Y, Leung A, Verghese J, Raghavan P. Effect of Auditory Constraints on Motor Learning Depends on Stage of Recovery Post Stroke. Frontiers in Neurology. (2014) 5:106. doi: 10.3389/fneur.2014.00106

62. Mazevet D, Meunier S, Pradat-Diehl P, Marchand-Pauvert V, PierrotDeseilligny E. Changes in propriospinally mediated excitation of upper limb motoneurons in stroke patients. Brain. (2003) 126:988-1000. doi: 10.1093/brain/awg088
63. Chen Y-T, Li S, DiTommaso C, Zhou P, Li S. Possible contributions of ipsilateral pathways from the contralesional motor cortex to the voluntary contraction of the spastic elbow flexors in stroke survivors: a TMS study. Am J Phys Med Rehabil. (2019). doi: 10.1097/PHM.0000000000001147. [Epub ahead of print].

64. Li S, Bhadane M, Gao F, Zhou P. The reticulospinal pathway does not increase its contribution to the strength of contralesional muscles in stroke survivors as compared to ipsilesional side or healthy controls. Front Neurol. (2017) 8:627. doi: 10.3389/fneur.2017.00627

65. Ellis MD, Drogos J, Carmona C, Keller T, Dewald JP. Neck rotation modulates flexion synergy torques, indicating an ipsilateral reticulospinal source for impairment in stroke. J Neurophysiol. (2012) 108:3096-104. doi: 10.1152/jn.01030.2011

66. Miller LC, Dewald JPA. Involuntary paretic wrist/finger flexion forces and EMG increase with shoulder abduction load in individuals with chronic stroke. Clin Neurophysiol. (2012) 123:1216-25. doi: 10.1016/j.clinph.2012.01.009

67. Ellis MD, Schut I, Dewald JPA. Flexion synergy overshadows flexor spasticity during reaching in chronic moderate to severe hemiparetic stroke. Clin Neurophysiol. (2017) 128:1308-14. doi: 10.1016/j.clinph.2017. 04.028

68. Gurari N, Drogos JM, Dewald JPA. Individuals with chronic hemiparetic stroke can correctly match forearm positions within a single arm. Clin Neurophysiol. (2017) 128:18-30. doi: 10.1016/j.clinph.2016.10.009

69. Ellis MD, Carmona C, Drogos J, Dewald JPA. Progressive abduction loading therapy with horizontal-plane viscous resistance targeting weakness and flexion synergy to treat upper limb function in chronic hemiparetic stroke: A randomized clinical trial. Front Neurol. (2018) 9:71. doi: 10.3389/fneur.2018.00071

70. McPherson JG, Chen A, Ellis MD, Yao J, Heckman CJ, Dewald JPA. Progressive recruitment of contralesional cortico-reticulospinal pathways drives motor impairment post stroke. J Physiol. (2018) 596:1211-25. doi: $10.1113 /$ JP274968

71. McPherson JG, McPherson LM, Thompson CK, Ellis MD, Heckman CJ, Dewald JPA. Altered neuromodulatory drive may contribute to exaggerated tonic vibration reflexes in chronic hemiparetic stroke. Front Hum Neurosci. (2018) 12:131. doi: 10.3389/fnhum.2018.00131

72. Lance JW. Symposium synopsis. In: Feldman RG, Young RR, Koella WP, editors. Spasticity: Disordered Motor Control. Chicago: Year Book Medical Publishers (1980). p. 485-94.

73. Pandyan AD, Gregoric M, Barnes MP, Wood D, Van Wijck F, Burridge J, et al. Spasticity: clinical perceptions, neurological realities and meaningful measurement. Disabil Rehabil. (2005) 27:2-6. doi: 10.1080/09638280400014576

74. Bucy PC, Keplinger JE, Siqueira EB. Destruction of the "pyramidal tract" in man. J Neurosurg. (1964) 21:285-98. doi: 10.3171/jns.1964.21.5.0385

75. Phillips CG, Porter R. Corticospinal Neruones. Their Role in Movement. New York, NY: Academic Press (1977).

76. Van Gijn J. The Babinski sign and the pyramidal syndrome. J Neurol Neurosurg Psychiatry. (1978) 41:865-73. doi: 10.1136/jnnp.41.10.865

77. Schreiner LH, Lindsley DB, Magoun HW. Role of brain stem facilitatory systems in maintenance of spasticity. J Neurophysiol. (1949) 12:207-16. doi: 10.1152/jn.1949.12.3.207

78. Bucy PC. Studies on the human neuromuscular mechanism. II effect of ventromedial cordotomy on muscular spasticity in man. Arch Neurol Psychiatry. (1938) 40:639-62. doi: 10.1001/archneurpsyc. 1938.02270100011001

79. Burke D, Knowles L, Andrews C, Ashby P. Spasticity, decerebrate rigidity and the clasp-knife phenomenon: an experimental study in the cat. Brain. (1972) 95:31-48. doi: 10.1093/brain/95.1.31

80. Bhadane MY, Gao F, Francisco GE, Zhou P, Li S. Correlation of resting elbow angle with spasticity in chronic stroke survivors. Front Neurol. (2015) 6:183. doi: $10.3389 /$ fneur.2015.00183

81. McPherson JG, Ellis MD, Heckman CJ, Dewald JPA. Evidence for increased activation of persistent inward currents in individuals with chronic hemiparetic stroke. J Neurophysiol. (2008) 100:3236-43. doi: $10.1152 /$ jn. 90563.2008 
82. Mottram CJ, Suresh NL, Heckman CJ, Gorassini MA, Rymer WZ. Origins of abnormal excitability in biceps brachii motoneurons of spastic-paretic stroke survivors. J Neurophysiol. (2009) 102:2026-38. doi: 10.1152/jn.00151.2009

83. Mottram CJ, Wallace CL, Chikando CN, Rymer WZ. Origins of spontaneous firing of motor units in the spastic-paretic biceps brachii muscle of stroke survivors. J Neurophysiol. (2010) 104:3168-79. doi: 10.1152/jn. 00463.2010

84. Heckmann CJ, Gorassini MA, Bennett DJ. Persistent inward currents in motoneuron dendrites: implications for motor output. Muscle Nerve. (2005) 31:135-56. doi: 10.1002/mus.20261

85. Gourab K, Schmit BD, Hornby TG. Increased lower limb spasticity but not strength or function following a single-dose serotonin reuptake inhibitor in chronic stroke. Arch Phys Med Rehabil. (2015) 96:2112-9. doi: 10.1016/j.apmr.2015.08.431

86. Seo NJ, Fischer HW, Bogey RA, Rymer WZ, Kamper DG. Effect of a serotonin antagonist on delay in grip muscle relaxation for persons with chronic hemiparetic stroke. Clin Neurophysiol. (2011) 122:796-802. doi: 10.1016/j.clinph.2010.10.035

87. McPherson JG, Ellis MD, Harden RN, Carmona C, Drogos JM, Heckman CJ, et al. Neuromodulatory inputs to motoneurons contribute to the loss of independent joint control in chronic moderate to severe hemiparetic stroke. Front Neurol. (2018) 9:470. doi: 10.3389/fneur.2018.00470

88. Nyberg-Hansen R. Origin and termination of fibers from the vestibular nuclei descending in the medial longitudinal fasciculus. An experimental study with silver impregnation methods in the cat. J Comp Neurol. (1964) 122:355-67. doi: 10.1002/cne.901220306

89. Miller DM, Klein CS, Suresh NL, Rymer WZ. Asymmetries in vestibular evoked myogenic potentials in chronic stroke survivors with spastic hypertonia: evidence for a vestibulospinal role. Clin Neurophysiol. (2014) 125:2070-8. doi: 10.1016/j.clinph.2014.01.035

90. Miller DM, Baker JF, Rymer WZ. Ascending vestibular drive is asymmetrically distributed to the inferior oblique motoneuron pools in a subset of hemispheric stroke survivors. Clin Neurophysiol. (2016) 127:2022-30. doi: 10.1016/j.clinph.2016.01.019

91. Brown P, Rothwell JC, Thompson PD, Britton TC, Day BL, Marsden CD. New observations on the normal auditory startle reflex in man. Brain. (1991) 114:1891-902. doi: 10.1093/brain/114.4.1891

92. McCall AA, Miller DM, Yates BJ. Descending influences on vestibulospinal and vestibulosympathetic reflexes. Front Neurol. (2017) 8:112. doi: 10.3389/fneur.2017.00112

93. Jankowska E, Edgley SA. How can corticospinal tract neurons contribute to ipsilateral movements? A question with implications for recovery of motor functions. Neuroscientist. (2006) 12:67-79. doi: 10.1177/1073858405 283392

94. Pundik S, Falchook AD, McCabe J, Litinas K, Daly JJ. Functional brain correlates of upper limb spasticity and its mitigation following rehabilitation in chronic stroke survivors. Stroke Res Treat. (2014) 2014:306325. doi: 10.1155/2014/306325

95. Ward NS, Cohen LG. Mechanisms underlying recovery of motor function after stroke. Arch Neurol. (2004) 61:1844-8. doi: 10.1001/archneur.61.12.1844

96. Di Pino G, Pellegrino G, Assenza G, Capone F, Ferreri F, Formica $\mathrm{D}$, et al. Modulation of brain plasticity in stroke: a novel model for neurorehabilitation. Nat Rev Neurol. (2014) 10:597-608. doi: $10.1038 /$ nrneurol.2014.162

97. Raffin E, Hummel FC. Restoring motor functions after stroke: multiple approaches and opportunities. Neuroscientist. (2018) 24:400-16. doi: $10.1177 / 1073858417737486$

98. Francisco GE, Li S. Spasticity. In: Cifu DX, editor. Physical Medicine and Rehabilitation. 5th ed. Philadelphia, PA: Elsevier (2015).

99. Fregosi M, Contestabile A, Hamadjida A, Rouiller EM. Corticobulbar projections from distinct motor cortical areas to the reticular formation in macaque monkeys. Eur J Neurosci. (2017) 45:1379-95. doi: $10.1111 /$ ejn.13576

100. Darling WG, Ge J, Stilwell-Morecraft KS, Rotella DL, Pizzimenti MA, Morecraft RJ. Hand motor recovery following extensive frontoparietal cortical injury is accompanied by upregulated corticoreticular projections in monkey. J Neurosci. (2018) 38:6323-39. doi: 10.1523/JNEUROSCI.0403-18.2018

101. Fregosi M, Contestabile A, Badoud S, Borgognon S, Cottet J, Brunet JF, et al. Changes of motor corticobulbar projections following different lesion types affecting the central nervous system in adult macaque monkeys. Eur J Neurosci. (2018) 48:2050-70. doi: 10.1111/ejn.14074

102. Jankowska E, Cabaj A, Pettersson LG. How to enhance ipsilateral actions of pyramidal tract neurons. J Neurosci. (2005) 25:7401-5. doi: 10.1523/JNEUROSCI.1838-05.2005

103. Kline TL, Schmit BD, Kamper DG. Exaggerated interlimb neural coupling following stroke. Brain. (2007) 130:159-69. doi: 10.1093/brain/awl278

104. Li S, Durand-Sanchez A, Latash ML. Inter-limb force coupling is resistant to distorted visual feedback in chronic hemiparetic stroke. J Rehabil Med. (2014) 46:206-11. doi: 10.2340/16501977-1256

105. Li S, Francisco GE, Zhou P. Post-stroke hemiplegic gait: new perspective and insights. Front Physiol. (2018) 9:1021. doi: 10.3389/fphys.2018.01021

106. Levin MF. Interjoint coordination during pointing movements is disrupted in spastic hemiparesis. Brain. (1996) 119:281-93. doi: 10.1093/brain/119.1.281

107. Shaikh T, Goussev V, Feldman AG, Levin MF. Arm-trunk coordination for beyond-the-reach movements in adults with stroke. Neurorehabil Neural Repair. (2014) 28:355-66. doi: 10.1177/1545968313510973

108. Levin MF, Liebermann DG, Parmet Y, Berman S. Compensatory versus noncompensatory shoulder movements used for reaching in stroke. Neurorehabil Neural Repair. (2016) 30:635-46. doi: $10.1177 / 1545968315613863$

109. Levin MF, Solomon JM, Shah A, Blanchette AK, Feldman AG. Activation of elbow extensors during passive stretch of flexors in patients with post-stroke spasticity. Clin Neurophysiol. (2018) 129:2065-74. doi: 10.1016/j.clinph.2018.07.007

110. Chen Y-T, Li S, Magat E, Zhou P, Li S. Motor overflow and spasticity in chronic stroke share a common pathophysiological process: analysis of within-limb and between-limb EMG-EMG coherence. Front Neurol. (2018) 9:795. doi: 10.3389/fneur.2018.00795

111. Brunnstrom S. Motor testing procedures in hemiplegia: based on sequential recovery stages. Phys Ther. (1966) 46:357-75. doi: 10.1093/ptj/46.4.357

112. Anzak A, Tan H, Pogosyan A, Brown P. Doing better than your best: Loud auditory stimulation yields improvements in maximal voluntary force. Exp Brain Res. (2011) 208:237-43. doi: 10.1007/s00221-010-2474-1

113. Anzak A, Tan H, Pogosyan A, Djamshidian A, Ling H, Lees A, et al. Improvements in rate of development and magnitude of force with intense auditory stimuli in patients with Parkinson's disease. Eur J Neurosci. (2011) 34:124-32. doi: 10.1111/j.1460-9568.2011.07735.x

114. Brownstone RM, Chopek JW. Reticulospinal systems for tuning motor commands. Front Neural Circuits. (2018) 12:30. doi: 10.3389/fncir.2018.00030

115. Valls-Solé J, Rothwell JC, Goulart F, Cossu G, Muñoz E. Patterned ballistic movements triggered by a startle in healthy humans. J Physiol. (1999) 516:931-8. doi: 10.1111/j.1469-7793.1999.0931u.x

116. Carlsen AN, Chua R, Inglis JT, Sanderson DJ, Franks IM. Can prepared responses be stored subcortically? Exp Brain Res. (2004) 159:301-9. doi: 10.1007/s00221-004-1924-z

117. Carlsen AN, Chua R, Dakin CJ, Sanderson DJ, Inglis JT, Franks IM. Startle reveals an absence of advance motor programming in a Go/No-go task. Neurosci Lett. (2008) 434:61-5. doi: 10.1016/j.neulet.2008.01.029

Conflict of Interest Statement: The authors declare that the research was conducted in the absence of any commercial or financial relationships that could be construed as a potential conflict of interest.

Copyright (C) 2019 Li, Chen, Francisco, Zhou and Rymer. This is an open-access article distributed under the terms of the Creative Commons Attribution License (CC $B Y)$. The use, distribution or reproduction in other forums is permitted, provided the original author(s) and the copyright owner(s) are credited and that the original publication in this journal is cited, in accordance with accepted academic practice. No use, distribution or reproduction is permitted which does not comply with these terms. 